\title{
Analysis of calcium carbonate polymorphs deposited in water piping system and the effect of tartaric acid additive
}

\author{
W. A. Putranto ${ }^{1, *}, Y$. Umardhani ${ }^{1}$, Sulistyo ${ }^{1}$, Yurianto ${ }^{1}$, and $A$. P. Bayuseno ${ }^{1}$ \\ 1 Department of Mechanical Engineering, Faculty of Engineering, Diponegoro University, \\ Tembalang Campus, Semarang 50275, Indonesia
}

\begin{abstract}
Calcium carbonate $\left(\mathrm{CaCO}_{3}\right)$ formed in a water piping system was investigated in the presence of chemical additives tartaric acid $(0.00$ and $10.00 \mathrm{ppm})$ and various temperatures $\left(\left(27\right.\right.$ and $\left.50^{\circ} \mathrm{C}\right)$. The flow rate inside pipe $(35 \mathrm{ml} / \mathrm{min})$ were selected. Solutions of $\mathrm{CaCl}_{2}$ and $\mathrm{Na}_{2} \mathrm{CO}_{3}$ were prepared in water with equimolar to $\mathrm{Ca}^{2+}$ concentration of $3000 \mathrm{ppm}$. The induction time of scale nucleation varied from $24 \mathrm{~min}$ to $44 \mathrm{~min}$. An increasing temperature of the solution resulted in more $\mathrm{CaCO}_{3}$ scale, mass, while the higher tartaric acid made the reduced mass of scales by $90 \%$. $\mathrm{SEM} / \mathrm{EDS}$ analysis verified $\mathrm{CaCO}_{3}$ with a plate like morphology. Also the XRPD Rietveld method provided the confirmation of a major phase of calcite and vaterite minerals followed by the minor of aragonite in the absence of tartaric acid and at room temperature. However, the presence of $10 \mathrm{ppm}$ tartaric acid yielded the increasing result of calcite, while aragonite precipitation was hampered under the influence of tartaric acid. The presence of tartaric acid at increasing temperature of $50^{\circ} \mathrm{C}$ could delay formation of calcite, whereas aragonite could be formed significantly. Thus the study showed the capacity of the tartaric acid in influencing $\mathrm{CaCO}_{3}$ crystallization.
\end{abstract}

\section{Introduction}

The mineral deposits of $\mathrm{CaCO}_{3}$ are commonly found in all types of water resources such as surface water, ground water, brackish water, seawater and wastewater. Generally, the $\mathrm{CaCO}_{3}$ crystallization can be found in many piping systems such as cooling water [4]. The scaling of pipes can reduce heat transfer performance and lead to high cost of maintenance [5]. The crystallization phenomenon follows three processes: supersaturation, nucleation and crystal growth. The saturated solution is the pre-condition and the driving force of the crystallization process which affects the rate of nucleation [6]. $\mathrm{CaCO}_{3}$ scale may be formed in three polymorph crystals: namely calcite, vaterite and aragonite, of which calcite is the most stable form at any temperatures $[1,7]$. Vaterite and aragonite, at given appropriate conditions, may eventually transform into calcite. [8]. Studies on the $\mathrm{CaCO}_{3}$ scaling in pipes are always associated with crystallization, which can be affected by many factors such as fluid flow rates, temperature and presence of chemical additives [9].

This paper discusses characteristics of calcium carbonate deposits formed in a water piping system due to the presence of additive of tartaric acid and under influence of various temperatures and the constant flow rate. SEM (Scanning Electron Microscope) / EDX (Energy Dispersive X-ray Spectrometry) was employed for examining the crystal deposits

\footnotetext{
*Corresponding author : wap_mesin@yahoo.co.id
} 
formed in the solution, while XRPD (X-ray powder diffraction) Rietveld was used to validate the crystalline form of calcium carbonate.

\section{Materials and Methods}

\section{$2.1 \mathrm{CaCO}_{3}$ crystal formation in solution}

Scaling experiments were performed using an experimental laboratory unit, which was equipped with a small diameter pipe section in which the laminar solution is flown by a water pump [2]. Equimolar solutions of $\mathrm{CaCl}_{2}$ and $\mathrm{Na}_{2} \mathrm{CO}_{3}$ were prepared for the crystal forming solution corresponding to $\mathrm{Ca}^{2+}$ concentration of $3000 \mathrm{ppm}$. The $\mathrm{CaCl}_{2}$ solution was made by dissolving $\mathrm{CaCl}_{2}$ crystals in distilled water at room temperature and $\mathrm{Na}_{2} \mathrm{CO}_{3}$ solution was prepared in the same way. The tartaric acid $\left(\mathrm{C}_{4} \mathrm{H}_{6} \mathrm{O}_{6}\right)$ crystal as an additive $(10$ ppm) was added to the $\mathrm{Na}_{2} \mathrm{CO}_{3}$ solution. The reaction of the scaling process can be expressed as (Eq.1):

$$
\mathrm{CaCl}_{2}(\mathrm{aq})+\mathrm{Na}_{2} \mathrm{CO}_{3}(\mathrm{aq}) \rightarrow \mathrm{CaCO}_{3}(\mathrm{~s})+2 \mathrm{NaCl}(\mathrm{aq})
$$

In the experimental run, five litters each of $\mathrm{CaCl}_{2}$ and $\mathrm{Na}_{2} \mathrm{CO}_{3}$ solutions were initially added into a vessel (1 and 2) respectively. The solutions from vessel ( 1 and 2$)$ were then transported into a vessel ( 3 and 4) used the pump system (5 and 6). The solutions of $\mathrm{CaCl}_{2}$ and $\mathrm{Na}_{2} \mathrm{CO}_{3}$ on vessel ( 3 and 4 ) were simultaneously entered into the coupon house (7) which contained five coupons made of copper. The solutions of $\mathrm{CaCl}_{2}$ and $\mathrm{Na}_{2} \mathrm{CO}_{3}$ were expected to react in the coupons (which were designed specifically for the growth of the $\mathrm{CaCO}_{3}$ scale). The solution out of the coupon house was continuously monitored by a conductivity meter for three hours, i.e. until the end of the experimental run. At the end of the experiment, valve for connecting the coupon house and the vessel ( 3 and 4) was closed for one hour. After one hour the coupons were removed from the coupon house and dried in the oven at $80^{\circ} \mathrm{C}$ for one hour. The coupons were weighed after cooled (difference weight of the coupon after and before testing was the mass of the scale).

The nucleation and crystal growth of $\mathrm{CaCO}_{3}$ was observed by measuring the change in the solution conductivity. The first nucleation form was signed by a sudden decrease in the value of conductivity of the solution (induction time), indicating that a large number of ions forming the crystals begin to leave the solution to form crystals.

\subsection{Characterization of $\mathrm{CaCO}_{3}$ scale}

Scale precipitated on the coupons of samples was then examined by SEM/EDX for morphology and elemental analysis.The SEM test was employed to determine the morphology of crystals, likely hexagonal (vaterite), orthorhombic (aragonite) and trigonal (calcite). The EDX test was used to determine the chemical composition percentages of the scale formed.

Further, the XRPD Rietveld method was selected for phase composition examination. Scan parameters chosen for measurements were: $10-90^{\circ}, 2 \theta, 0.020$ steps and $15 \mathrm{~s} / \mathrm{steps}$. Peak position and peak intensity were identified using the feature finder or on the screen in the software. The data obtained were compared with the ratio of PC based search data base program, Philips X'Pert Software (Philips Electronics NV) is used to detect the possibility of crystalline phase in the sample. In this approach, the peak position is automated using the diffraction minima in the second derivate of diffraction traces. The peak positions and heights were checked against XRPD standard for $\mathrm{CaCO}_{3}$. The XRPD Rietveld program in the software validated the presence of crystal formed qualitatively and quantitatively. 


\section{Results and Discussion}

\subsection{Induction time and mass of scale}

In the present research, stable concentrations could be fixed at $3000 \mathrm{ppm}$ of $\mathrm{Ca}^{2+}$ in the solution by means of constant stirring in all experiments. Also, experiments were conducted with the laminar flow rate (Reynolds number, NRE \pm 180 ), of which the flow rate 35 $\mathrm{ml} / \mathrm{min}$, two variations of temperature $\left(27\right.$ and $\left.50^{\circ} \mathrm{C}\right)$ and also two variations of tartaric acid concentrations $(0.00$ and $10.00 \mathrm{ppm})$ were selected. The induction time of $\mathrm{CaCO}_{3}$ scale formation is given in Figure 1.

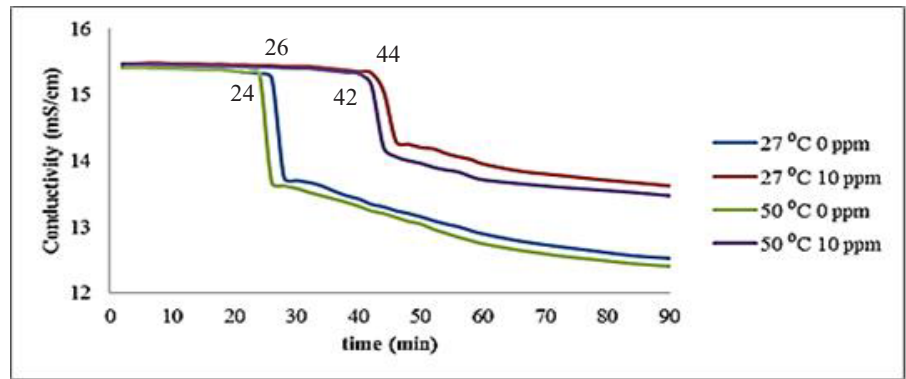

Fig. 1. Plot of conductivity versus time of scaling at flow rate $35 \mathrm{ml} / \mathrm{min}$.

It is demonstrated that the reaction between $\mathrm{CaCl}_{2}$ and $\mathrm{Na}_{2} \mathrm{CO}_{3}$ solutions occurred as can be seen from the decline in conductivity of the solution coming out of the coupon house. The conductivity of the solution at first stabilized and then decreased suddenly. The time between mixing the solution to decrease in the conductivity could be fluctuated in accordance with the parameters investigated. This time interval is commonly called as the induction time. Obviously, the presence of additive $(10 \mathrm{ppm})$ made the increasing induction time, thereby delaying the crystal growth of calcium carbonate.

Table 1. Mass of the scales produced during the experiments

\begin{tabular}{|c|c|c|c|c|c|}
\hline \multirow{2}{*}{ No } & \multirow{2}{*}{$\begin{array}{c}\text { Mass of scales } \\
\text { (wt. gr) }\end{array}$} & \multicolumn{2}{|c|}{ Additive at $27^{\circ} \mathrm{C}$} & \multicolumn{2}{|c|}{ Additive at $50^{\circ} \mathrm{C}$} \\
\cline { 3 - 6 } & & $0 \mathrm{ppm}$ & $10 \mathrm{ppm}$ & $0 \mathrm{ppm}$ & $10 \mathrm{ppm}$ \\
\hline 1 & Calcium Carbonate & 0.1608 & 0.0166 & 0.1771 & 0.0153 \\
\hline
\end{tabular}

The $\mathrm{CaCl}_{2}$ and $\mathrm{Na}_{2} \mathrm{CO}_{3}$ solutions were met in the coupons and reacted to form $\mathrm{CaCO}_{3}$ scale. This can be seen that the mass of scale production is presented in Table 1. The scale mass results could be varied depending on the variation of testing parameters. The mass product reduced in the presence of additive, while increasing temperature led to increasing the mass scales.

\subsection{Effects of temperature and additive in the crystal forming solution}

The temperature and additive (absence and presence of tartaric acid) affect significantly the induction time and mass scale formed. The higher the temperature caused to the decreasing induction time, simply increasing the mass scale would be produced. In contrast, the presence of additive could be delayed the crystal formation and reduced the mass of scales (Figure 1, Table 1). Correspondingly, the parameters $\left(27^{\circ} \mathrm{C}, 0 \mathrm{ppm}\right)$ versus $\left(50^{\circ} \mathrm{C}, 0 \mathrm{ppm}\right)$ provided the decreasing of induction time from 26 to 24 minutes, while the mass on the 
scale increasing from 0.1608 to 0.1771 gr $(9.2 \%)$. This occurs because the higher temperature leads to the more energy in the molecules or ions and produces a faster rate of reaction.

Instead the higher concentrations of tartaric acid were added, the mass scale would be the less. In this way, the parameters $\left(27^{\circ} \mathrm{C}, 0 \mathrm{ppm}\right)$ versus $\left(50^{\circ} \mathrm{C}, 10 \mathrm{ppm}\right)$ lead to the increasing of induction time from 26 to 42 minutes, but mass scale decreased from 0.1608 to $0.0153 \mathrm{gr}(90.5 \%)$. This is because more core crystals is prevented from reaching a critical size, thereby reducing the number ions forming crystals. Here the mass crystal reduced consequently. Moreover, temperature affect the crystallization of $\mathrm{CaCO}_{3}$ scale. At temperatures $<30^{\circ} \mathrm{C}$, the pure amorphous $\mathrm{CaCO}_{3}$ (ACC) may transform into calcite via vaterite, while at the temperature of $\geq 40^{\circ} \mathrm{C}$, the pure ACC may turn into aragonite through vaterite [9].

\subsection{Characterization of the $\mathrm{CaCO}_{3}$ scale}

In the present study, $\mathrm{CaCO}_{3}$ crystal morphology can be examined using SEM (Figure 2). It shows a clear difference in the formation of $\mathrm{CaCO}_{3}$ crystals. At $\left(27^{\circ} \mathrm{C}, 0.00 \mathrm{ppm}\right)$ on left, crystal morphology was observed on the spot, namely vaterite (ball irregular) and calcite (rhombohedral). However, at $\left(50^{\circ} \mathrm{C}, 10 \mathrm{ppm}\right)$ on right, aragonite crystals are shown (flower shape) including calcite. The high temperature and the high ppm tartaric acid may alter the crystal morphology of vaterite into aragonite. Consequently, tartaric acid is highly effective for use in changing the crystal morphology of the $\mathrm{CaCO}_{3}$ crystals.

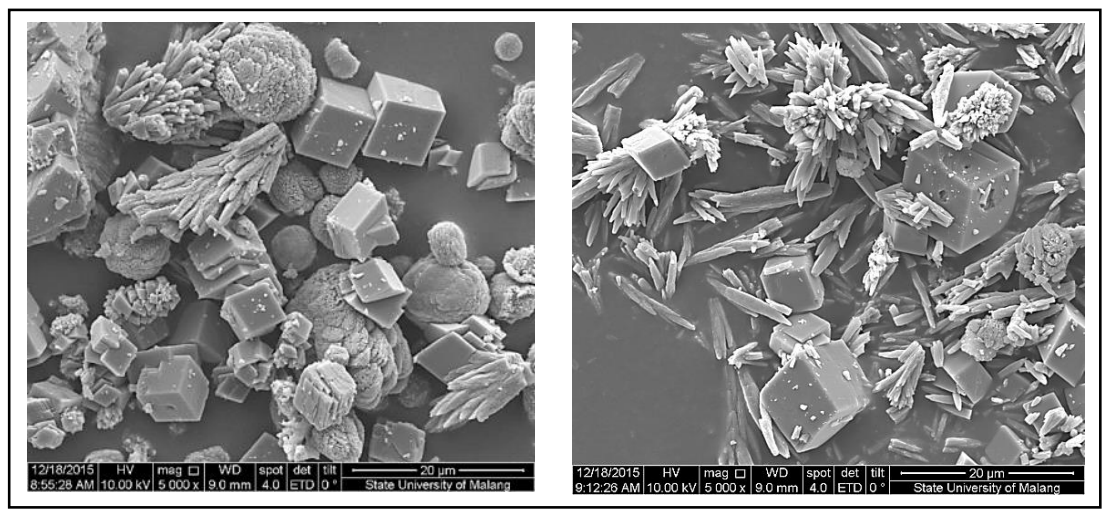

Fig. 2. Morphology of $\mathrm{CaCO}_{3}$ crystals produced at $27^{\circ} \mathrm{C}$ in the absence of tartaric acid (left), and at $50^{\circ} \mathrm{C}$ in the presence of tartaric acid $10 \mathrm{ppm}$ (right).

The chemical composition of the $\mathrm{CaCO}_{3}$ crystal can be examined using the EDX data. It shows that the major elements of $\mathrm{Ca}, \mathrm{C}$ and $\mathrm{O}$ belongs to the $\mathrm{CaCO}_{3}$ crystal in the presence $10.00 \mathrm{ppm}$ tartaric acid. The weight percent (wt. \%) of chemical elements can be calculated as follows: $\mathrm{Ca}=47.49$ wt. $\%, \mathrm{C}=10.19$ wt. $\%, \mathrm{O}=40.33$ wt. $\%$. The difference between the weight percent of the actual theory as follows $\mathrm{Ca}=7.49 \mathrm{wt} . \%, \mathrm{C}=1.81 \mathrm{wt} . \%$ and $\mathrm{O}=7.67 \mathrm{wt} . \%$. From EDX analysis results, it can be concluded that the crystals formed is $\mathrm{CaCO}_{3}$ scale, because each weight percent of $\mathrm{Ca}, \mathrm{C}$ and $\mathrm{O}$ corresponds to a ratio of $1: 1$ : 3.

Phase composition of $\mathrm{CaCO}_{3}$ can be examined using XRPD data (Figure 3). XRD analysis can determine the crystal phase formed by comparing the data experiment with the database $\mathrm{CaCO}_{3}$ phase composition can be examined using XRPD data (Figure 3) and also by comparing the data experiment with the database (JCPDS). The XRPD test results are in the form of stripes (peak). The different plot (below) provides the direct experimental 
evidence of phase crystals formed in the presence of tartaric acid $10 \mathrm{ppm}$ and the different temperature $\left(27\right.$ and $\left.50^{\circ} \mathrm{C}\right)$. The presence of the tartaric acid at a temperature of $27^{\circ} \mathrm{C}$ (left) provided vaterite and calcite with the strongest peak at 27.03 20 (PDF \# 96-901-5899) and $29.38^{\circ} 2 \theta$ (PDF \# 96-210-0993). The presence of tartaric acid (10 ppm) at a temperature of $50^{\circ} \mathrm{C}$ (right) made the crystal phase of vaterite transformed into aragonite (PDF \# 96-5000086) and calcite. Mixing calcium chloride and sodium carbonate salt solutions at a temperature $\geq 40^{\circ} \mathrm{C}$ yield to deposit the first phase of ACC results in the coupons within a few minutes turned into aragonite. The rapid changes similar to the findings of subsequently aragonite transformed into calcite (the most thermodynamically stable polymorph) within a few hours [10]. Overall XRD analysis of the crystals of the scale was obtained in accordance with the powder diffraction data for calcium carbonate.

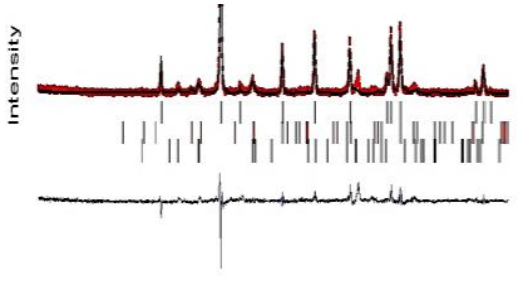

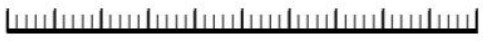

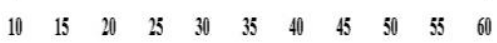

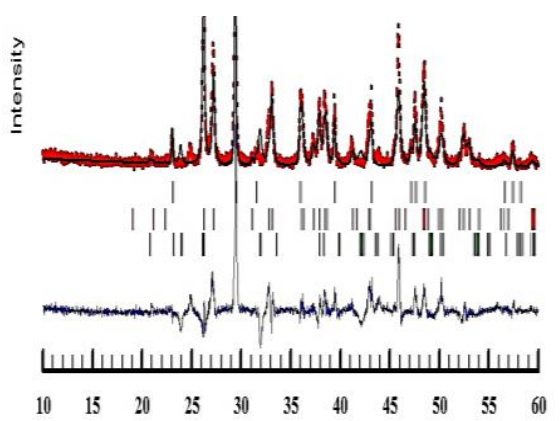

Fig. 3. XRPD Rietveld plots of crystals obtained at $27^{\circ} \mathrm{C}$ in the absence of tartaric acid (left), and at $50^{\circ} \mathrm{C}$ in presence of tartaric acid $10 \mathrm{ppm}$ (right). Peaks are given color: blue (calcite), red (aragonite) and green (vaterite).

Table 2. Phase composition of carbonate scale obtained at the laminar flow rate of $35 \mathrm{ml} / \mathrm{min}$

\begin{tabular}{|c|c|c|c|c|c|}
\hline \multirow{2}{*}{ No } & $\begin{array}{c}\text { Phase composition } \\
\text { (wt. \%) }\end{array}$ & \multicolumn{2}{|c|}{ Additive at $27^{\circ} \mathrm{C}$} & \multicolumn{2}{c|}{ Additive at $50^{\circ} \mathrm{C}$} \\
\cline { 3 - 6 } & Calcite & $0 \mathrm{ppm}$ & $10 \mathrm{ppm}$ & $0 \mathrm{ppm}$ & $10 \mathrm{ppm}$ \\
\hline 1 & 80.19 & 81.78 & 30.42 & 23.79 \\
\hline 2 & Aragonite & 7.30 & - & 69.58 & 15.81 \\
\hline 3 & Vaterite & 12.52 & 18.22 & - & 60.41 \\
\hline
\end{tabular}

Table 2 presents that calcite is the only major mineral formed at a low temperature of $27^{\circ} \mathrm{C}$ in the absence and presence of additive. Apparently calcite is more stable in the low temperature, while the temperature of $50^{\circ} \mathrm{C}$ makes the reduction of the amount of calcite formed in the solution accordingly. More metastable phases of such aragonite and vaterite may be easily formed in this temperature, whether the absence and presence of additive are in the solution.

\section{Conclusion and Remarks}

The experiment of calcium carbonate scale formation $\left(\mathrm{CaCO}_{3}\right)$ has been conducted. $\mathrm{CaCO}_{3}$ scale formation in pipes was affected by the solution temperature and tartaric acid. The temperature negatively affects the induction time, but the tartaric acid positively affects the induction time. The higher the temperature caused the shorter the induction time. Shorter induction time for higher temperature might be caused by more scale forming component being able to react to form the scale. On the other hand, the higher the tartaric acid concentration caused longer induction time. This may be due to the disruption activity of 
the tartaric acid molecules on the formation of $\mathrm{CaCO}_{3}$ crystals, hence the scale formation is inhibited. Tartaric acid in ppm amount and temperature was found to change the crystal phase of $\mathrm{CaCO}_{3}$ (vaterite to aragonite). $\mathrm{CaCO}_{3}$ scale formation by the addition of the tartaric acid at the temperature of $27^{\circ} \mathrm{C}$ produce vaterite phase (ball irregular) and slightly calcite phase (rhombohedral). With the addition of the tartaric acid at the temperature of $50^{\circ} \mathrm{C}$ to produce aragonite phase (flower shape) and a little amount of calcite. Of all the results showed tartaric acid can be used as an effective antiscalant to the scale of calcium carbonate in the various water piping system.

Authors grateful to the Laboratory of Physical Metallurgy Diponegoro University that has given the place during the experiment. The research grant provided by the Diponegoro University is also much appreciated. The authors would like to appreciate the comments useful and the kind suggestions from the anonymous reviewers

\section{References}

1. J. Garcia-Carmona, J. Gomez-Morales, J. Fraile-Sainz, R. Rodriguez-Clemente, Morphological characteristics and aggregation of calcite crystals obtained by bubbling $\mathrm{CO}_{2}$ through a $\mathrm{Ca}(\mathrm{OH})_{2}$ suspension in the presence of additives. Powder Technology, 130, 307-315 (2003)

2. S. Muryanto, A. P. Bayuseno, W. Sediono, W. Mangestiyono, Sutrisno. Development of a versatile laboratory project for scale formation and control, Education for Chemical Engineers, 7, e78-e84. (2012).

3. D. J. Tobler, J. D. Rodriguez Blanco, K. Dideriksen, K. K. Sand, N. Bovet, L. G. Benning, L. S. Stipp. The effect of aspartic acid and glycine on amorphous calcium carbonate (ACC) structure, stability and crystallization. Procedia Earth and Planetary Science, 10, 143 - 148. (2014).

4. Tzotzi,C., Pahiadaki,T., Yiantsios,S.G., Karabelas, A.J.,Andritsos,N. A study of $\mathrm{CaCO} 3$ scale formation and inhibitionin RO and NF membrane processes. Journal of Membrane Science, 296, 171-184. (2007).

5. Chao, Y., Horner, O., Hui, F., Lédion, J., Perrot, H. Direct detection of calcium carbonate scaling via a pre-calcified sensitive area of a quartz crystal microbalance. Desalination, 352, 103-108. (2014).

6. Sousa, M.F., Bertran,C.A. New methodology based on staticlight scattering measurements for evaluation of inhibitors for in bulk crystallization. Journal of Colloid and Interface Science, 420, 57-64. (2014).

7. Kladi, A., Klepetsanis, P.G., Østvold, T., Kontoyiannis, C. G., Koutsoukos, P.G. Crystal growth of calcium carbonate in seawater. The effect of temperature and of the presence of inhibitors, in: Z. Amjad (Ed.), Advances in Crystal Growth Inhibition Technologies, Kluwer Academic Publishers, New York etc., 85-106. (2002).

8. MacAdam, J., Parsons, S. A. Calcium carbonate scale control, effect of material and inhibitors. Water Sci. Technol, 49, 153-159. (2004).

9. Tobler, D. J., Rodriguez Blanco, J. D., Dideriksen, K., Sand, K. K., Bovet, N., Benning, L. G., Stipp, L. S. The effect of aspartic acid and glycine on amorphous calcium carbonate (ACC) structure, stability and crystallization. Procedia Earth and Planetary Science, 10, 143 - 148. (2014).

10. Altay, E., Shahwan, T., Tanoglu, M. Morphosynthesis of $\mathrm{CaCO} 3$ ad different reaction temperatures and the effect of PDDA, CTAB, and EDTA on the particle morphology and polimorph stability. Powder Technology, 178, 194-202. (2007). 